Full Length Article

\title{
Enhancement of combustion performance in a microchannel: Synergistic effects of bluff-body and cavity
}

\author{
Zheng Zhang ${ }^{\mathrm{a}, \mathrm{d}}$, Kun Wu ${ }^{\mathrm{b}}$, Wei Yao ${ }^{\mathrm{b}, \mathrm{c}}$, Richard Yuen ${ }^{\mathrm{d}}$, Jian Wang ${ }^{\mathrm{a}, *}$ \\ ${ }^{a}$ State Key Laboratory of Fire Science, University of Science and Technology of China, Hefei, Anhui 230026, PR China \\ ${ }^{\mathrm{b}}$ State Key Laboratory of High Temperature Gas Dynamics, Institute of Mechanics, Chinese Academy of Sciences, Beijing 100190, PR China \\ ${ }^{\mathrm{c}}$ School of Engineering Science, University of Chinese Academy of Science, Beijing 100049, PR China \\ ${ }^{\mathrm{d}}$ Department of Civil and Architectural Engineering, City University of Hong Kong, Kowloon, Hong Kong
}

\section{A R T I C L E I N F O}

\section{Keywords:}

Micro-combustor

Bluff-body

Cavity

Combustion performance

Flame-flow interaction

\begin{abstract}
A B S T R A C T
The stable flame is vulnerable in the micro-scale combustors due to the significant heat loss and the limited residence. In this study, the bluff-body and cavity are integrated in a microchannel to enhance the combustion performance of premixed $\mathrm{H}_{2}$ /air flames. The enhancement and combustion characteristics are investigated numerically, using detailed chemical kinematic mechanisms and conjugate heat transfer. It is found that the reaction zones formed behind the bluff-body in center is merged with the flame anchored by the cavity along the side wall, which converts the single flame tip in the micro cavity-combustor to the "M-type" flame. Moreover, the side dual-cavity configuration can significantly improve the anchorage ability of the central bluff-body through extending the recirculation zone and mitigating the flame stretch rate. Due to the synergistic effects of the bluff-body and cavity, the critical velocity increases from $40 \mathrm{~m} / \mathrm{s}$ in both the single cavity and the single bluff-body combustors to $56 \mathrm{~m} / \mathrm{s}$ in the proposed combustor. Improved wall temperature uniformity is also observed as the result of the merged reaction zones. Besides, the effects of the equivalence and blockage ratios are investigated. Results suggest that a moderate equivalence ratio is favored to achieve a stable and high efficiency combustion. As the blockage ratio of the bluff-body increases, the flame stability improved due to the enlarged recirculation zones, whereas the combustion efficiency degrades because of the strengthened flame stretch rate and reduced residence time. Finally, an optimal blockage ratio of 0.4 is proposed for the dualstabilizer micro-combustor.
\end{abstract}

\section{Introduction}

Recently, the increasing demand for portable electronic and mechanical equipment motivated the research interests in miniaturization of the power source. Over the last ten or so years, various micro-scale devices powered by combustion have been designed by virtue of microfabrication techniques, such as the "micro thrusters", the "micro engines" and the "micro thermophotovoltaic (micro-TPV)" [1]. The main advantages of the combustion-based compact power supply system are the larger energy density and the much shorter recharge time compared with the battery packages [2]. However, with the downscaling of the reaction chamber, heat and radical loss will be incurred as a result of large surface to volume ratio [3,4]. Additionally, comparing with normal scale systems, the residence time of reactants will remarkably reduce and become comparable to the characteristic time scales of chemical reaction in small scale combustors. Consequently, the combustion efficiency and flame stability will be significantly deteriorated, and in the worst cases a blow-off may occur [5]. Numerous efforts have been made to achieve a stable combustion in micro-scale reactors. Heat management is the vital strategy to suppress the heat loss for micro-scale combustors [6]. Several heat recirculation approaches, such as the "Swiss-roll" [7,8], the multichannel method $[9,10]$, and the porous medium $[11,12]$ have been developed to promote the flame stability through preheating the fresh reactants by the heat transferred from combustion zone. The coupling between catalytic and homogeneous combustion has also been investigated [13-15], the thermal and chemical effects of catalytic reactions improved the flame stability and conversion rate of the fuel, and the radical quenching can be counterbalanced by intensive catalytic reactions.

However, under high inflow velocity conditions, the heat recirculation and catalytic combustion approaches are incapable to sustain a stable flame as the limited residence time of reactants in microcombustors, i.e. the low Damköhler number. Therefore, various flame

\footnotetext{
* Corresponding author.

E-mail address: wangj@ustc.edu.cn (J. Wang).
} 


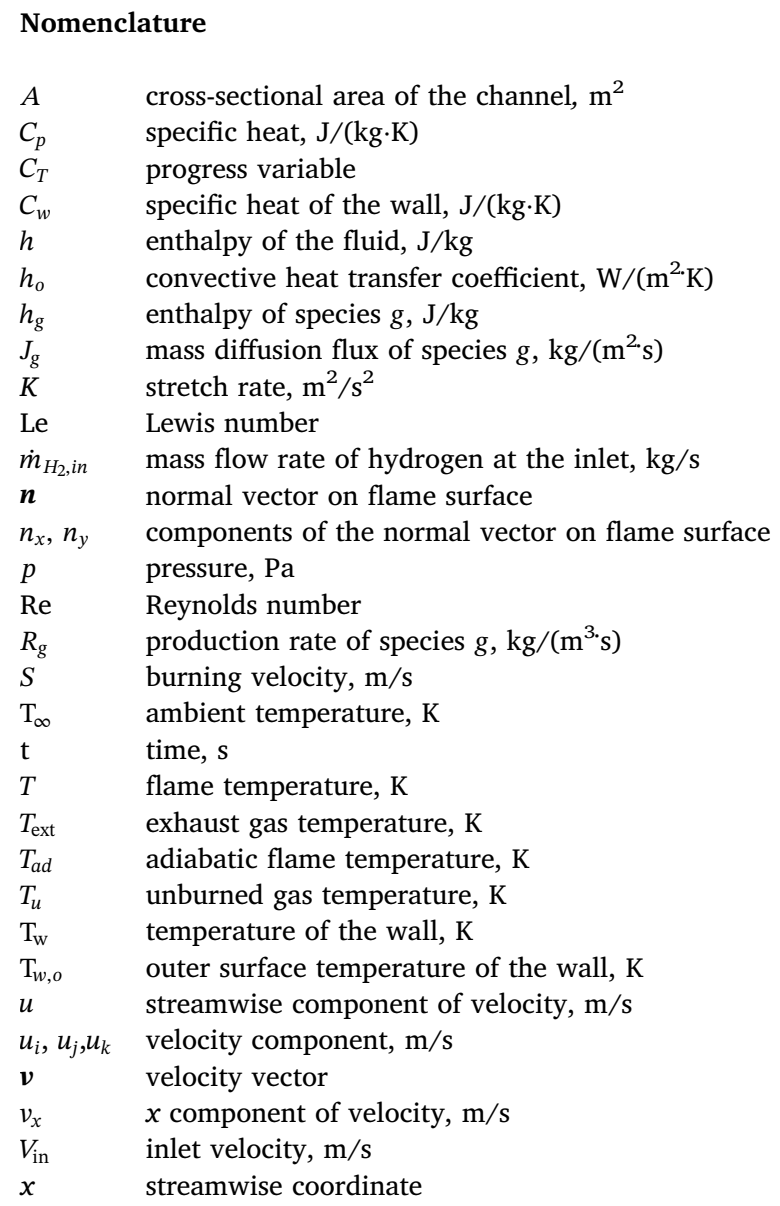

$\begin{array}{ll}x_{i}, x_{j}, x_{k} & \begin{array}{l}\text { coordinates in rectangular coordinate system } \\ \text { transverse coordinate }\end{array} \\ Y_{H_{2}} & \text { mass fraction of the species } \mathrm{H}_{2} \\ Y_{\mathrm{OH}} & \text { mass fraction of the species } \mathrm{OH} \\ Y_{g} & \text { mass fraction of speciesg }\end{array}$

Greek symbols

$\begin{array}{ll}\Delta H_{\text {total }} & \text { normalized total enthalpy change } \\ \delta & \text { channel height, mm } \\ \delta A & \text { area of flame surface element, } \mathrm{m}^{2} \\ \varepsilon & \text { surface radiative emissivity } \\ \eta_{c} & \text { combustion efficiency } \\ \eta_{r} & \text { conversion ratio of hydrogen } \\ \theta & \text { aft angle of the cavity, } 45^{\circ} \\ \lambda & \text { thermal conductivity of the gas mixture, } \mathrm{W} /(\mathrm{m} \cdot \mathrm{K}) \\ \lambda_{w} & \text { thermal conductivity of the wall, } \mathrm{W} /(\mathrm{m} \cdot \mathrm{K}) \\ \mu & \text { dynamic viscosity, } \mathrm{kg} /(\mathrm{m} \cdot \mathrm{s}) \\ \rho & \text { density, } \mathrm{kg} / \mathrm{m}^{3} \\ \rho_{w} & \text { density of the wall, } \mathrm{kg} / \mathrm{m}^{3} \\ \sigma & \text { Stephan-Boltzmann constant, } \mathrm{W} /\left(\mathrm{m}^{2} \cdot \mathrm{K}^{4}\right) \\ \phi & \text { equivalence ratio } \\ \omega & \text { edge length of the bluff-body }\end{array}$

Abbreviation

BC bluff-body and cavity coupled combustor

BD bluff-body combustor

BR blockage ratio

CA cavity combustor

RZ-B recirculation zone behind the bluff-body

RZ-C recirculation zone inside the cavity holders, e.g., backward step [16-19], bluff-body [20-22], and cavity [23-26] are widely used to stabilize the flame by increasing the flow residence time and providing hot reaction products as well as active radicals in the recirculation zone. Yang et al. [17] introduced the backward step in micro-cylindrical combustors for the micro-TPV system. They proved that backward step configurations can stabilize the flame under a high inlet velocity and a wide-range equivalence ratio. Khandelwal et al. [16] and Peng et al. [18] demonstrated that the multisteps configuration significantly improves the power output and the operation limits compared with single step. In addition to the backward step configurations applied under relative low inlet velocity such as the micro-TPV systems, the bluff-body and cavity based micro-combustors were designed to stabilize the flame under relative high inlet velocities. Wan and coauthors introduced the central bluff-body to stabilize the $\mathrm{H}_{2}$ /air [20] and $\mathrm{CH}_{4}$ /air [27] flames in a microchannel, where a fivefold increase was observed in the blow-off limit of the $\mathrm{H}_{2}$ /air premixed flame. The comparative studies between different bluff-body configurations, such as the wall-blade type [21] and the side-slitted type [22], provide optimization methods for bluff-body based micro-combustors. Furthermore, the plate type bluff-body is coupled with pre-heating channels to further improve the flame stability through the heat and flow recirculation [28,29]. The cavity was applied by Li et al. [23] in a catalyst micro-combustor, the synergistic effects between the cavity stabilization and catalyst combustion enhanced the stability of the methane flames significantly. The non-catalytic micro-combustors with dual-cavity have also been investigated $[24,25]$. The results show that, the dual-cavity structure can anchor the flame roots safely under inlet flow velocities several times larger than the critical velocity in planar micro-combustors without cavity. Despite of the excellent capability in the flame stabilizing, the performances of cavity and bluff-body based micro-combustors deteriorate significantly under high inlet velocities. The flame anchored by the central bluff-body will be prolonged and shrinks to the center region, leading to the decrease in the combustion efficiency [20] and a local high wall temperature [22]. With the increase of inlet velocity, the flame stabilized by cavity expands towards the side wall and tends to split around the tip accompanied by a considerable leakage of fuel [24].

In this study, the bluff-body and cavity combined configuration is applied in a microchannel. The coupling effects between the flames anchored by the central bluff-body and the side cavity is expected to improve the combustion performance compared to the conventional bluff-body and cavity based combustors. The blow off limits, combustion efficiency and the outer wall temperature are numerically investigated with detailed chemical kinematic mechanisms and conjugate heat transfer. The mechanisms of enhanced combustion of the proposed micro-combustor are analyzed with regard to the flow and flame interaction and heat flux between flame and wall. The effect of blockage ratio of bluff-body is also investigated as the crucial parameter in flame stabilization.

\section{Numerical methodology}

\subsection{Combustor geometry}

The combustor combined with bluff-body and cavity configurations (abbreviated as BC) is shown in Fig. 1(a), where the end of the bluffbody is aligned with the entrance of the dual-cavity. The flame anchored behind the bluff-body is expected to interact with that formed in the cavity to enhance the combustion intensity and suppress the flame splitting near the tip. Two conventional micro-combustors with only a 


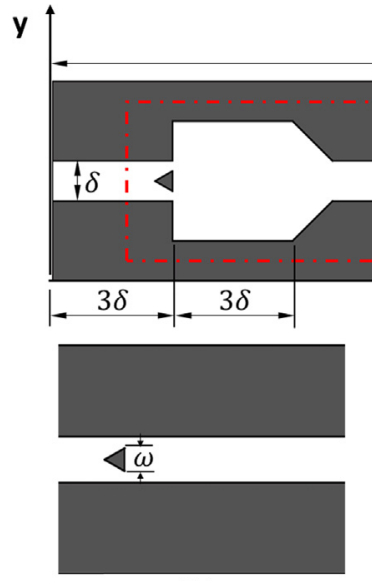

(b)
$18 \delta$

(a)
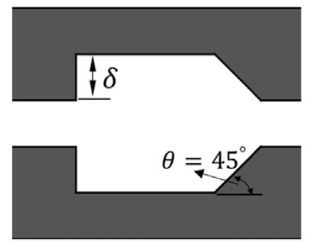

(c)
Fig. 1. Schematics of the combustors with various flame holders: (a) bluff-body and cavity combined (BC) (b) single bluff body (BD), (c) dual- cavity (CA).

bluff body (abbreviated as BD) or a cavity (abbreviated as CA) are also investigated for comparison. The overall sizes of the three different combustors are the same, with only different flame-holding structures denoted by the red rectangular. Fig. 1(b) and (c) illustrates the corresponding flame-holding structures of BD and CA combustors, respectively. The channel height $(\delta)$ is $1 \mathrm{~mm}$. The edge length $(\omega)$ of the regular triangle in $\mathrm{BD}$ is fixed at $0.5 \mathrm{~mm}$, while varies with the adjustable blockage ratio $\left(\mathrm{BR}=\frac{\omega}{\delta}\right)$ for the $\mathrm{BC}$ case.

\subsection{Numerical approach}

The $\mathrm{H}_{2}$ /air premixed flame and the conjugate heat transfer within the combustors shown in Fig. 1 are simulated using a two dimensional (2D) modeling with a detail mechanism [30]. Turbulence modeling is required for $\operatorname{Re}>500$ as pointed out by Kuo and Ronney [8]. The characteristic length scale of the proposed combustor is the channel height $(\delta=1 \mathrm{~mm}$ ), while the lowest velocity to be considered is $12 \mathrm{~m} /$ $\mathrm{s}$, leading to a Re number much larger than 500 , which necessitates the modeling of turbulence. The realizable $k-\varepsilon$ turbulent model is adopted, the capability has been confirmed by previous studies on bluffbody [20] and cavity [31] anchored micro-combustions. To simplify the numerical model, several assumptions are considered: (a) The radiation within flame and solid wall are ignored, (b) no work done by viscosity and pressure,(c) the Dufour effect is ignored, (d) the effects of gravity on the heat and mass transport are not considered. The resulting governing equations of heat and mass transfer are solved:

$\frac{\partial \rho}{\partial \mathrm{t}}+\frac{\partial \rho u_{i}}{\partial x_{i}}=0$

$\frac{\partial \rho u_{j}}{\partial \mathrm{t}}+\frac{\partial}{\partial x_{i}}\left(\rho u_{i} u_{j}\right)=\frac{\partial}{\partial x_{i}}\left[\mu\left(\frac{\partial u_{j}}{\partial x_{i}}+\frac{\partial u_{i}}{\partial x_{j}}\right)\right]-\frac{2}{3} \frac{\partial}{\partial x_{i}}\left(\mu \frac{\partial u_{k}}{\partial x_{k}}\right)-\frac{\partial p}{\partial x_{j}}$

$\frac{\partial \rho h}{\partial \mathrm{t}}+\frac{\partial}{\partial x_{i}}\left(\rho u_{i} h\right)=\frac{\partial}{\partial x_{i}}\left(\frac{\lambda}{C_{p}} \frac{\partial h}{\partial x_{i}}\right)+\sum_{g}\left[\frac{\partial}{\partial x_{i}}\left(h_{g} J_{g}\right)\right]+\sum_{k} h_{g} R_{g}$

$\frac{\partial \rho Y_{g}}{\partial \mathrm{t}}+\frac{\partial}{\partial x_{i}}\left(\rho u_{i} Y_{g}\right)=\frac{\partial J_{g}}{\partial x_{i}}+R_{g}$

where $\rho$ is the density, $u$ the velocity and $p$ the pressure, the subscript $i$, $j$ and $k$ indicate the coordinate directions; $\mu$ and $h$ denote the dynamic viscosity and total enthalpy of the mixture; $C_{p}$ and $\lambda$ are the specific heat and thermal conductivity; $Y_{g}, J_{g}$ and $R_{g}$ are the mass fraction, mass diffusion flux and the production of species $g$, respectively. The physical properties of species and mixture are calculated with methods as follows $[6,15,20]$ : The incompressible idea gas law is applied for the gas density, the $\lambda$ and $u$ of mixture are derived from individual species with the ideal-gas mixing law. The specific heat of species is calculated with a piecewise polynomial fit of temperature. The other properties of individual species including, thermal conductivity, mass diffusivity and viscosity are determined by the kinetic-theory.

The heat transfer inside the wall is considered since the significant effects of thermal coupling in micro-combustions [3-5], which is calculated by

$\frac{\partial\left(\rho_{w} C_{w} T_{w}\right)}{\partial t}=\frac{\partial}{\partial x_{i}}\left(\lambda_{w} \frac{\partial T_{w}}{\partial x_{i}}\right)$

where $\rho_{w}, C_{w}$ and $\lambda_{w}$ denote the properties of the solid wall as defined in gas mixture, $T_{w}$ is the wall temperature.

The inflow of the combustor is defined as velocity inlet, where the premixed $\mathrm{H}_{2}$ /air with uniform inlet velocity $\left(V_{\text {in }}\right)$ distribution and initial temperature of $300 \mathrm{~K}$ is specified, the equivalence ratio $(\phi)$ is set to 0.5 unless specifically stated. At the outlet, the zero Neumann boundary with ambient pressure is imposed. The coupled wall thermal condition (equal heat flux in two side) is applied on the interfaces between fluid and wall. The non-slip and inert wall conditions are specified on the interfaces. Besides, the heat transfer between the outersurfaces and ambient is calculated by

$q=h_{o}\left(T_{W, O}-T_{\infty}\right)+\varepsilon \sigma\left(T_{W, O}^{4}-T_{\infty}^{4}\right)$
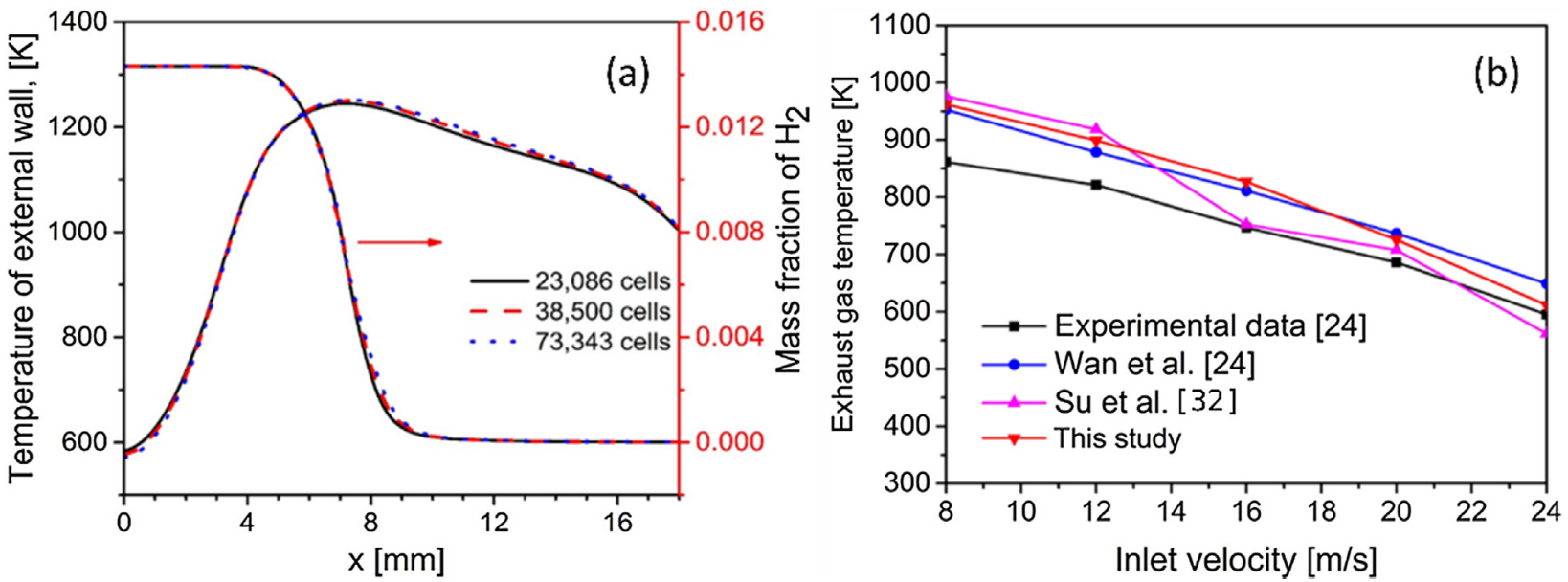

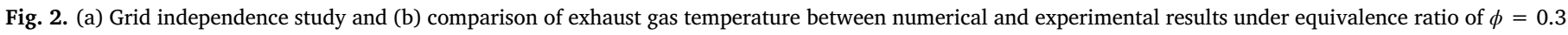
under various inlet velocities. 
where $h_{o}, \varepsilon$ and $T_{\infty}$ are the convective heat transfer coefficient, the surface emissivity of the quartz wall and the ambient temperature, with the constant fixed value of $20 \mathrm{~W} /\left(\mathrm{m}^{2} \cdot \mathrm{K}\right), 0.92$ and $300 \mathrm{~K}$, respectively [24]. The Stephan-Boltzmann constant $\sigma=5.67 \times 10^{-8} \mathrm{~W} /\left(\mathrm{m}^{2} \cdot \mathrm{K}^{4}\right)$. The 2D model for reacting flow and heat transfer in wall is solved using the CFD software ANSYS-Fluent v18.2. Second order upwind scheme is applied for the discretization of the convention terms. The pressurevelocity linkage is solved with the SIMPLE algorithm. The mixture is ignited through patching a high temperature region within the cavity zone under a relative low inlet velocity. The governing equations are solved until the relative residuals decrease to $10^{-6}$ for energy and to $10^{-3}$ for others.

\subsection{Grid independence study and numerical validation}

The multi-block structured quadrilateral mesh is adopted to discrete the computational domain with refinement near the shear layers. Three sets of grid system are applied in the CA combustor for the grid independence assessment at $V_{\text {in }}$ of $10 \mathrm{~m} / \mathrm{s}$. The results of grid independence study are shown in Fig. 2(a). The well agreements indicate the convergence of the computational grid. Therefore, the medium level grid system of 38,500 cells (overall average spacing of $50 \mu \mathrm{m}$ ) is used in the subsequent modeling as a balance of computational cost and numerical accuracy. Moreover, the profile of the exhaust gas temperature versus inlet velocity of the CA combustor is compared with the experimental and the numerical data in Ref. [24,32], as shown in Fig. 2(b). The predictions show good agreements with the experimental results and comparable to the numerical results in previous studies. Therefore, a reliable simulation results is expected in the following study by the present computational methodology, especially at high inflow velocities, the main concerned region for this study.

\section{Results and discussion}

\subsection{Flame features}

The typical flame features of the BC combustor are shown in Fig. 3. Two pairs of vortex structures are formed behind the central flame stabilizer and in the dual-cavity, regardless of the inlet velocity. The flame is anchored in the recirculation zones as indicated by the large amount of $\mathrm{OH}$ radical in Fig. 3. The dimensionless combustion progress variable $C_{T}=\frac{\mathrm{T}-\mathrm{T}_{\mathrm{u}}}{\mathrm{T}_{\mathrm{ad}}-\mathrm{T}_{\mathrm{u}}}$ related to the local flame temperature $\mathrm{T}$, unburned mixture temperature $T_{u}$, and adiabatic flame temperature $T_{a d}$, is adopted to define the flame front [33]. The white contour line with $C_{T}=0.6$, visualizes the fame front. The flame front line shows that two types of flame structures, the "M-type" flame and "double-V" flame, can be observed with increasing $V_{i n}$. At relative low inlet velocities, the reaction zones anchored by cavity and bluff-body are merged to form the "M-type" flame, which is prolonged and extend out of cavity with inlet velocity as shown in Fig. 3(a) and (b). The flame front is stretched especially near the cavity aft where the flow velocity and strain rate increase rapidly. Eventually the flame is split near the cavity aft at a relative high velocity. As a result, the "M-type" flame is transferred into the "double-V" flame at high inflow velocity as seen in Fig. 3(c). As the $V_{\text {in }}$ increases, the concentration of the $\mathrm{OH}\left(Y_{\mathrm{OH}}\right)$ reduces, indicating a decrease of combustion intensity. It is noted that, unlike the flame tip of the "M-type", the "double-V" flame is prolonged significantly and approaches the exit of the combustor, where the flame tip tends to split similar to the "tip-opening" phenomenon observed in previous microcavity combustors [24].

\subsection{Comparison between combined and conventional micro-combustors}

\subsubsection{Performance assessment of different micro-combustors}

As concerned in the introduction, combustion efficiency $\left(\eta_{c}\right)$ and flame stability are the most important metrics for application and safety of micro-combustors. The conversion ratio of hydrogen, $\eta_{r}$, is defined by

$\eta_{r}(x)=\frac{\dot{m}_{\mathrm{H}_{2}, \text { in }}-\int \rho v_{x} Y_{\mathrm{H}_{2}} d A}{\dot{m}_{\mathrm{H}_{2}, \text { in }}}$

Here $\dot{m}_{\mathrm{H}_{2} \text {,in }}$ is the mass flow rate of the hydrogen at the inlet, $\rho$ denotes the mixture density, $v_{x}$ the $x$ component of velocity, $Y_{\mathrm{H}_{2}}$ the mass fraction of $\mathrm{H}_{2}$. The $\eta_{c}$ is determined by the conversion ratio at the outlet, $\eta_{c}=\eta_{r}(x=18)$.

As presented in Fig. 4, the $\eta_{c}$ decreases with increasing inlet velocity for both combustors. At low inlet velocities of $V_{\text {in }}<16 \mathrm{~m} / \mathrm{s}$, the discrepancy between different combustors is generally small, and the hydrogen is almost completely consumed with $\eta_{c}>99 \%$. With a further increase of $V_{\text {in }}$, the combustion efficiency of the two conventional combustors decrease rapidly comparing with a lower decline of the BC combustor. The critical inlet velocities correspond to the appearance of "Split off" and "Tip opening" for the conventional and BC micro-combustors are marked. The flame "Split off" and "Tip opening" phenomena are induced by the high flame strain rates near the end of the recirculation zone and the flame tip for the $\mathrm{BD}$ and CA combustors respectively, as shown in Fig. 6. The flame split off and tip opening occur both at $V_{i n}=40 \mathrm{~m} / \mathrm{s}$ for the BD and CA combustors. For the BC micro-combustor, the "Split off" and "Tip opening" phenomenon occur at $V_{\text {in }}=56$ and $58 \mathrm{~m} / \mathrm{s}$ respectively, accompanied with an observable decrease in combustion efficiency.

The temperature uniformity and the exhaust gas temperature are also key parameters effecting the system efficiency of combustion based micro-scale systems, e.g., the micro-TPV [17] and micro-turbine [34]. The profiles of outer wall $\left(\mathrm{T}_{\mathrm{W}}\right)$ and exhaust gas $\left(\mathrm{T}_{\mathrm{ext}}\right)$ temperature for the CA, BD and BC combustors are illustrated in Fig. 5. It can be clearly found that $\mathrm{CA}$ and $\mathrm{BC}$ combustors have higher and more uniform $\mathrm{T}_{\mathrm{W}}$. The profiles of $T_{W}$ remain almost the same under various velocities for the $\mathrm{BC}$ combustor. As regards the BD case, the wall temperature is lower and less uniform, with high-temperature zones shrink obviously with increased inlet velocity, which is mainly due to the prolonged flame zone as observed in previous experiments [20]. For the exhaust temperature, the $\mathrm{BD}$ and $\mathrm{BC}$ combustors have larger $\mathrm{T}_{\mathrm{ext}}$ than the $\mathrm{CA}$ combustor as shown in Fig. 5b. The lower $\mathrm{T}_{\mathrm{W}}$, indicating the lower heat loss according to Eq. (6), in the BD combustor and the higher $\eta_{c}$ of the BC combustor can account for the higher $\mathrm{T}_{\text {ext }}$ observed in them. As the $V_{\text {in }}$ increases from $20 \mathrm{~m} / \mathrm{s}$ to $36 \mathrm{~m} / \mathrm{s}$, the $\mathrm{T}_{\text {ext }}$ of the CA and BD combustors

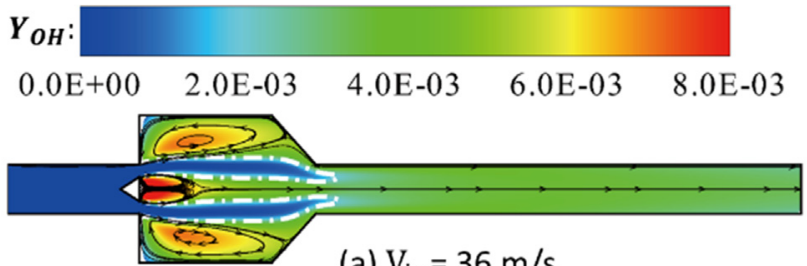

(a) $V_{\text {in }}=36 \mathrm{~m} / \mathrm{s}$

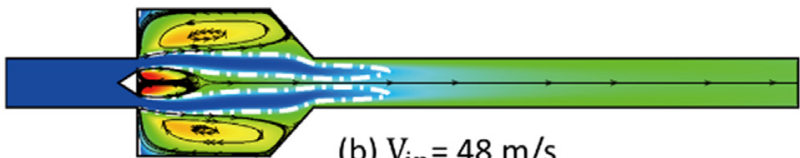

(b) $V_{\text {in }}=48 \mathrm{~m} / \mathrm{s}$

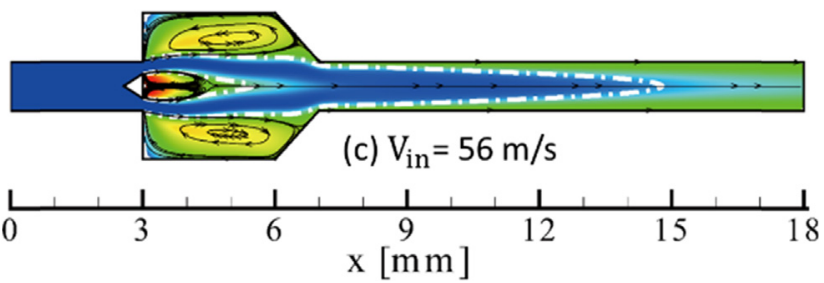

Fig. 3. Flow and flame structures in $\mathrm{BC}$ combustor under various inlet velocities. 


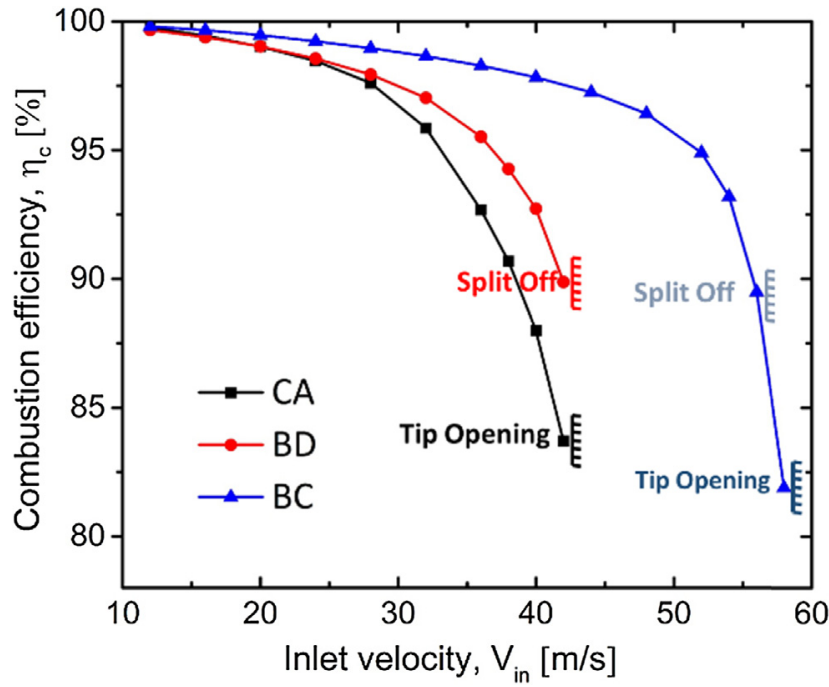

Fig. 4. Variation of combustion efficiency with inlet velocity and the limit inlet velocities for different micro-combustors.

decrease significantly with the drop of $\eta_{c}$ as the $V_{\text {in }}$ increases. However, a growth followed by reduction tendency of the $T_{\text {ext }}$ is observed for the BC combustor as the combustion efficiency decreases gradually. The heat loss ratio decreases due to the increase of total chemical energy input and an almost constant heat loss rate indicated by the steady $\mathrm{T}_{\mathrm{W}}$, which can explain the increase of $\mathrm{T}_{\text {ext }}$ observed in the $\mathrm{BC}$ combustor as the $V_{\text {in }}$ increases from $20 \mathrm{~m} / \mathrm{s}$ to $28 \mathrm{~m} / \mathrm{s}$. At $V_{\text {in }}=36 \mathrm{~m} / \mathrm{s}$, the BC combustor has the highest $\mathrm{T}_{\text {ext }}$, which is $132 \mathrm{~K}$ higher than the CA combustor and $33 \mathrm{~K}$ higher than the $\mathrm{BD}$ combustor. The results presented in Fig. 5 show the advantage of the BC micro-combustor for micro-TPV and micro-turbine systems due to the uniform yet high outer wall temperature and high exhaust gas temperature.

The temperature distributions and the flame fronts for different micro-combustors at $V_{\text {in }}=36 \mathrm{~m} / \mathrm{s}$ are demonstrated in Fig. 6 . The side cavities provide high-temperature products near the inner wall, which contribute to the uniform and high $\mathrm{T}_{\mathrm{W}}$ of the $\mathrm{BC}$ and CA combustors. The flame stabilized behind the central bluff-body leads to higher exhaust temperatures in the $\mathrm{BD}$ and $\mathrm{BC}$ micro-combustors. The length of the flame front of the $\mathrm{BC}$ combustor is much shorter than those in the conventional micro-combustors, which is coincident with the improved combustion efficiency in Fig. 4. The variations of consumption ratio of the fuel along the streamwise direction at the $V_{\text {in }}$ of $36 \mathrm{~m} / \mathrm{s}$ are depicted in Fig. 7. Even though the consumption ratio at the outlet (combustion

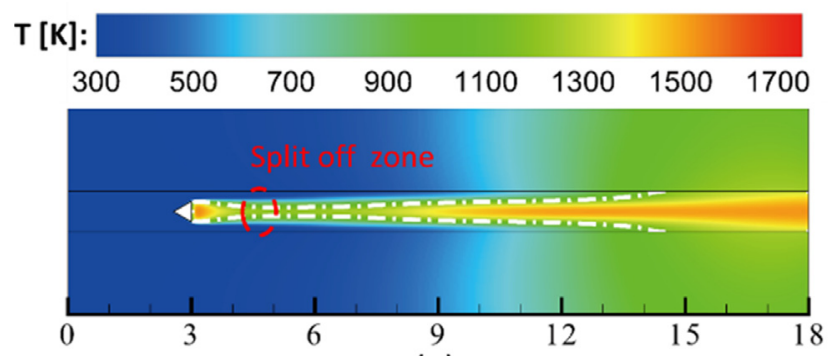

(a)

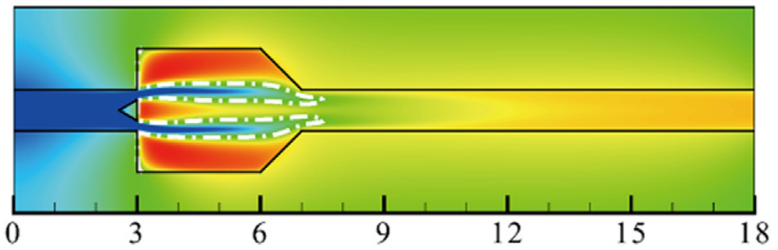

(b)

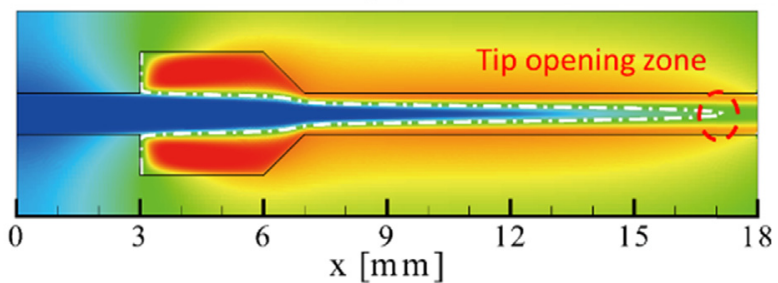

(c)

Fig. 6. Temperature contours with flame front (white dash lines) for (a) BD, (b) $\mathrm{BC}$ and (c) CA combustors at $V_{\text {in }}=36 \mathrm{~m} / \mathrm{s}$.

efficiency) is close between different micro-combustors, the proposed $\mathrm{BC}$ micro-combustor shows a much higher increase rate of the consumption ratio, with most of the hydrogen has been consumed within the cavity zone $(\mathrm{x}=3-7 \mathrm{~mm})$. Within the cavity region, the $\eta_{r}$ of the $\mathrm{BC}$ combustor exceeds the sum of those of the CA and BD combustors.

The effects of the $\phi$ on the performance of three types of combustors are investigated as shown in Fig. 8. As the $\phi$ increased from 0.4 to 0.5 , the limits of tip-opening and split-off are both extended for different combustors. The BC combustor has the largest critical velocity among them independent with the $\phi$. The most remarkable improvement on the flame stability is observed at $\phi=0.5$. The variation of the $\eta_{c}$ of the BC combustor with increasing velocity for different $\phi$ is depicted in Fig. 8(b). The profiles show the similar trend for different equivalence ratios except at the critical velocities, where the tip opening occurred
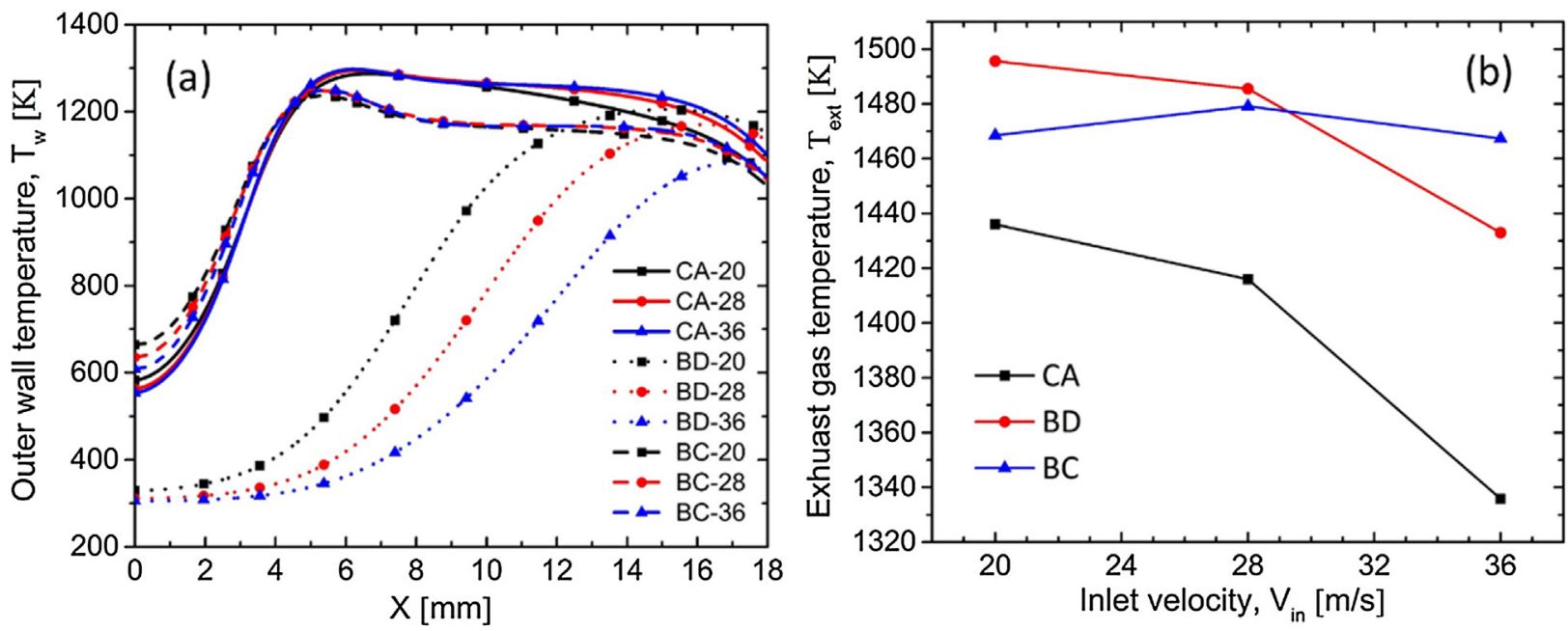

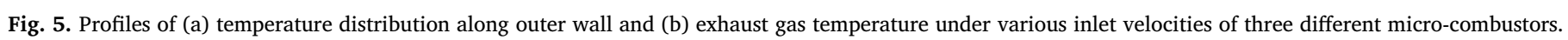




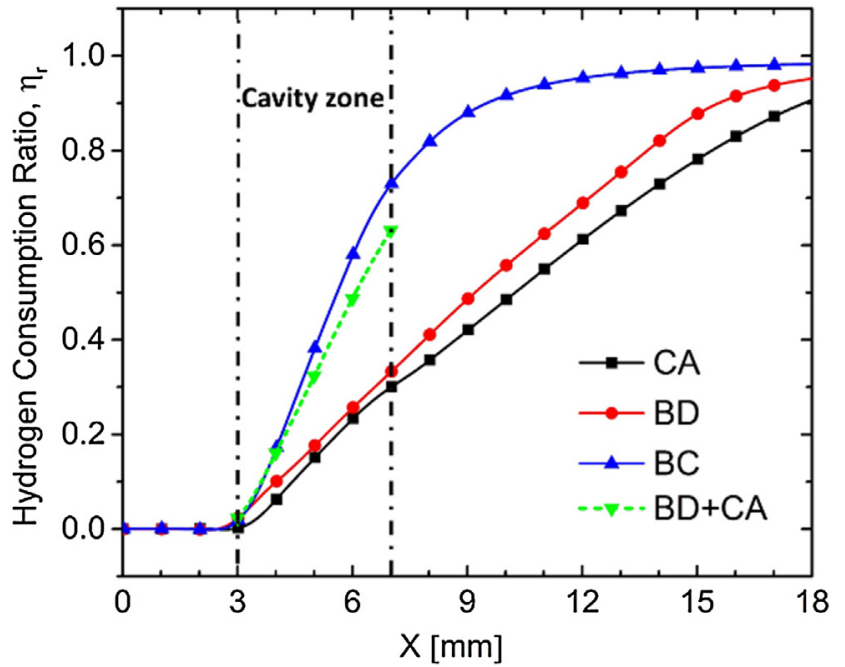

Fig. 7. Variations of hydrogen consumption ratio along streamwise direction at $V_{\text {in }}=36 \mathrm{~m} / \mathrm{s}$.

immediately with the flame split behind the bluff-body for $\phi=0.6$. The higher $\phi$ enhances the flame stability at high velocity, whereas the lower $\eta_{c}$ is observed at the relative low velocity as reported in [20]. The increasing of the amount of fuel accounts for the lower $\eta_{c}$. Therefore, a moderate $\phi$ is favored to achieve a stable and high efficiency flame in the $\mathrm{BC}$ combustor.

Overall, the comparison of the combustion performance between the conventional and the $\mathrm{BC}$ micro-combustors shows that the bluffbody and cavity structures integrated in BC have synergetic effects in improving the combustion efficiency, flame stability and temperature distributions. In the following sections, the underlying mechanisms of the synergetic effects in terms of flow, flame interaction and heat loss rate will be scrutinized.

\subsubsection{Flow and flame interactions near recirculation zones}

The contour of $Y_{\mathrm{OH}}$ with representative streamlines in upper part and the contour of $\mathrm{H}_{2}$ with contour lines of $\mathrm{x}$-component velocity $v_{x}$ in lower part are shown in Fig. 9 at $V_{\text {in }}=36 \mathrm{~m} / \mathrm{s}$. The recirculation zone formed behind the bluff-body (RZ-B) in the BC combustor is obviously larger than the one in the BD combustor, which is in agreement with the

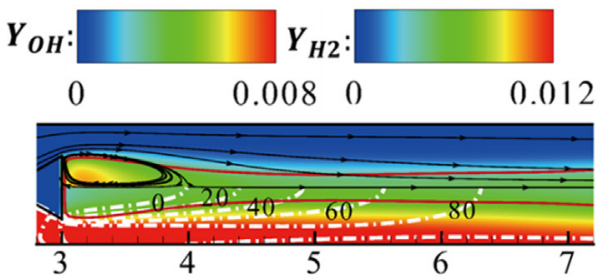

(a)

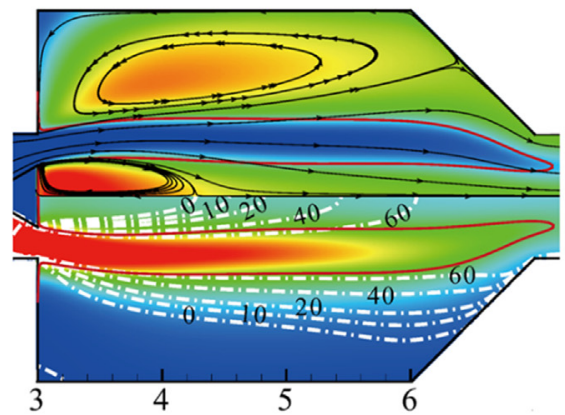

(b)

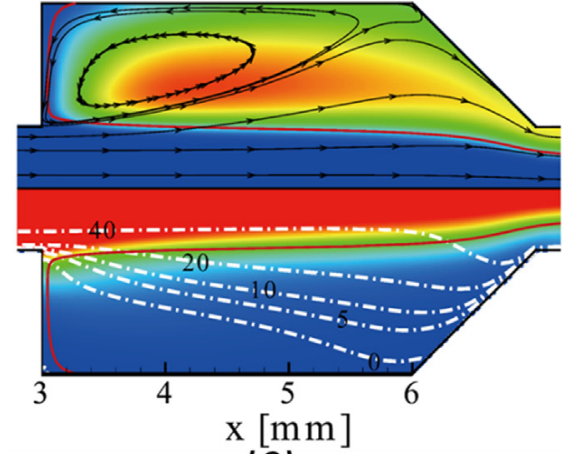

(C)

Fig. 9. Contours of $Y_{O H}$ overlaid with streamlines (upper part) and Contours of $Y_{\mathrm{H}_{2}}$ overlaid with contour lines of $x$-component velocity $v_{x}$ (lower part) of (a) BD, (b) BC and (c) CA combustors at $V_{i n}=36 \mathrm{~m} / \mathrm{s}$. The red lines are the flame fronts indicated with $C_{T}=0.6$. (For interpretation of the references to colour in this figure legend, the reader is referred to the web version of this article.)

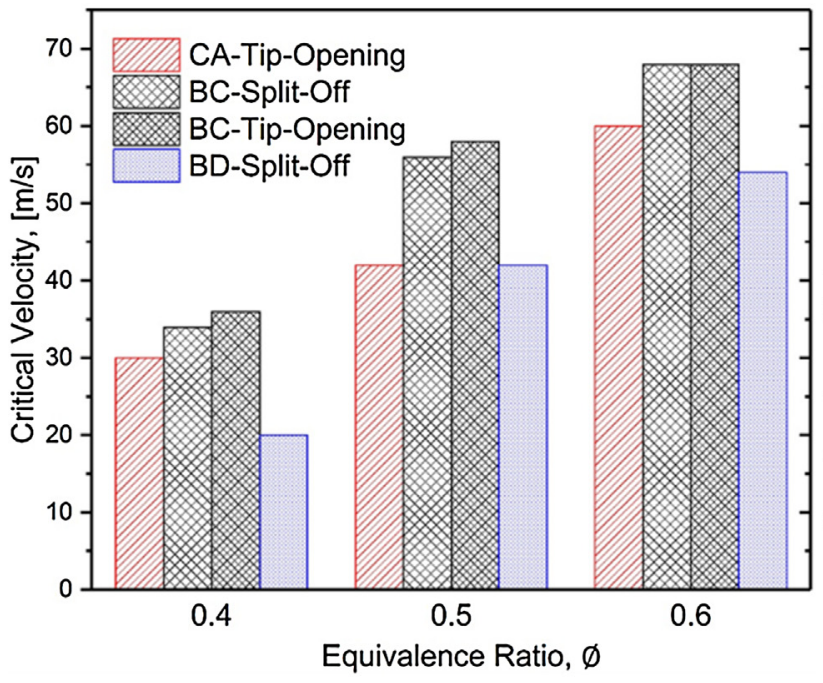

(a)

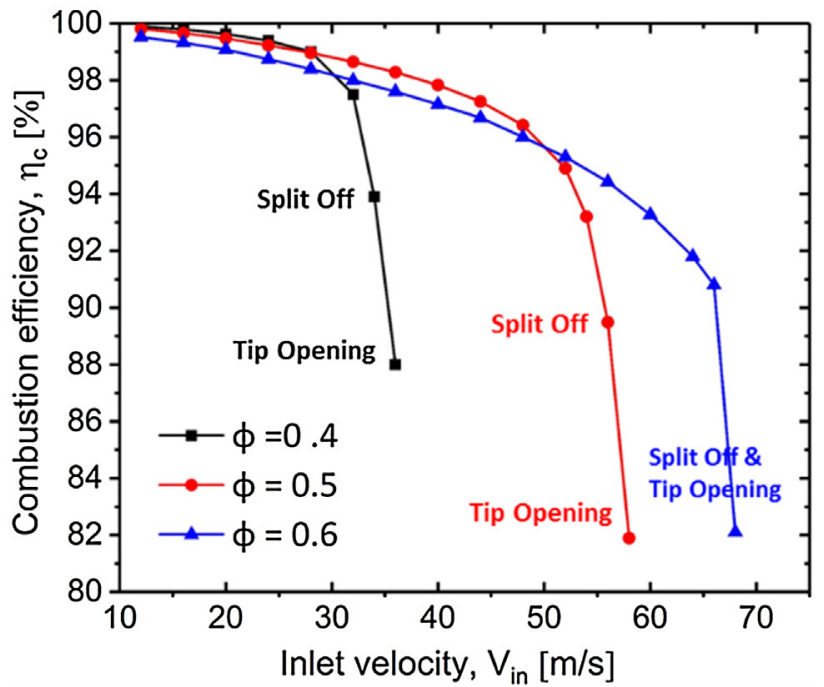

(b)

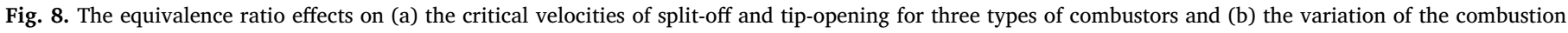
efficiency with increasing velocity of the BC combustor. 
expanding of recirculation region in a similar flame-holder observed by $\mathrm{Xu}$ et al. [35] and can be explained by the retardance of the vorticity formation by the stronger viscous stresses in the narrower channel [36]. The $\mathrm{BC}$ combustor has a significantly higher $Y_{\mathrm{OH}}$ in the RZ-B than that that in the BD combustor. In the BD case, the flame front (red sold line) has an evident neck zone behind the recirculation zone, while the flame front behind the bluff-body shows a weak curvature for the $\mathrm{BC}$ combustors. Comparing the situations in cavity zones between $\mathrm{BC}$ and $\mathrm{CA}$ combustors, a larger recirculation zone inside the cavity (RZ-C) is observed for the $\mathrm{BC}$ combustion, which is mainly due to a larger velocity at the entrance of the cavity. Nevertheless, a lower $Y_{\mathrm{OH}}$ was obtained in the cavity of BC combustor, especially near the aft of the cavity. Entrained by the recirculated flow, the flame front near the entrance and the aft of the cavity in the BC case becomes concave toward the unburned mixture.

To have a further understanding of the interactions between flow and flame structures induced by the different flame holders, the flame stretch rate, $K$ was calculated at flame front shown in Fig. 9 following the definition in [37],

$K=\frac{1}{\delta A} \frac{d(\delta A)}{d t}=-\boldsymbol{n n}: \nabla \boldsymbol{v}+\nabla \cdot \boldsymbol{v}+\boldsymbol{S} \nabla \cdot \boldsymbol{n}$

where $\delta A$ denotes the flame surface element, $\boldsymbol{n}$ is the normal vector, $\boldsymbol{v}$ is the velocity vector, and $\boldsymbol{S}$ is the burning velocity. For a steady state flame, the value of $\boldsymbol{S}$ is equal to the corresponding normal component of $\boldsymbol{v}$. For two-dimensional scenario, the stretch rate can be reduced as follow $[38,39]$ :

$K=n_{x} n_{y}\left(\frac{\partial u}{\partial y}+\frac{\partial v}{\partial x}\right)+n_{y}^{2} \frac{\partial u}{\partial x}+n_{x}^{2} \frac{\delta v}{\delta y}-\left(u n_{x}+v n_{y}\right)\left(\frac{d n_{x}}{d x}+\frac{d n_{y}}{d y}\right)$

The first two terms of the right hand side of Eq. (9) are present the stretch rate induced by strain $\left(K_{S}\right)$, and the last term denotes the contribution of flame-front curvature $\left(K_{c}\right)$. Where $n_{x}$ and $n_{y}$ are determined by the fitted high order polynomial curve $y=f(x)$, the normal vector $\boldsymbol{n}$ can be computed as:

$\boldsymbol{n}=\left(\frac{-f^{\prime}(x)}{\sqrt{1+\left(f^{\prime}(x)\right)^{2}}}, \frac{1}{\sqrt{1+\left(f^{\prime}(x)\right)^{2}}}\right)$

The flame stretch profiles and the components of that induced by strain and curvature near the recirculation zones of different combustors are shown in Fig. 10. As pointed out by Kedia et al. [40] the effects of stretch rate near the root of recirculation zone should be considered carefully as the unconventional flame structure formed due to the "negative burning velocity". As shown in Fig. 9(a) and (b), the flame fronts stabilized by the bluff-body are partly embedded in the recirculation region, where the direction of the transverse velocity, $V_{y}$, along the flame front is from the burned side to the unburned side, indicating the "negative burning velocity". Therefore, the stretch profiles were depicted eliminating the negative burning velocity region near the bottom of bluff-body. There is a negative stretch portion near the recirculation zone RZ-B for both $\mathrm{BD}$ and $\mathrm{BC}$ cases, which is mainly due to the strong shear flow along the flame front aside the recirculation zones as shown in Fig. 10. It has been confirmed that a negative stretch rate tends to weaken the combustion intensity of the premixed flame with the Lewis number, Le $<1$, as the lean premixed hydrogen/ air flames applied in this study, and vice versa [41]. Accordingly, the stronger negative stretch rate can explain the lower $Y_{\mathrm{OH}}$ in the RZ-B in the $\mathrm{BD}$ combustor compared with the $\mathrm{BC}$ case. Whereas a larger positive flame stretch rate is observed in regions behind the reticulation location for BD combustor, where the flame splits with increased inlet velocities. The high positive $K$ is dominated by the $K_{s}$, owing to the large flow strain rate generated by the high velocity gradient as shown in Fig. 9(a), where the large amount of unburned $\mathrm{H}_{2}$ indicates incomplete combustion. Correspondingly, $Y_{\mathrm{OH}}$ further decreases and contributes to the receding of the flame front to the central low-velocity region, finally leading to the pinch-off of the flame behind the recirculation zone under the critical inlet velocity. As regards the cavity-stabilized flame, the CA combustor possesses a positive stretch rate within the whole cavity zone, while negative stretch rates are observed at most parts of the flame fronts in the cavity zone for the $\mathrm{BC}$ case, particularly near the end of the cavity. As shown in Fig. 10(b), the significant negative $K$ observed in the cavity of the $\mathrm{BC}$ case are dominated by the contribution of flame curvature, $K_{c}$, whereas the positive $K$ of the CA case is mainly due to the contribution of strain, $K_{s}$, along the flame front. Therefore, the higher $Y_{\mathrm{OH}}$ is observed in most regions of the cavity in the CA combustor comparing to that of the $\mathrm{BC}$ combustor. For the region near the cavity entrance, the excessive positive stretch rate exists in the CA case, which leads to the incomplete combustion and therefore a lower $Y_{\mathrm{OH}}$ near the cavity entrance as shown in Fig. 9(c).

\subsubsection{The conjugate heat transfer analysis}

The thermal coupling between flame and wall plays a significant role in flame stability [6] and the performance of the micro-scale combustors [9]. The variation of the total enthalpy change of the gas
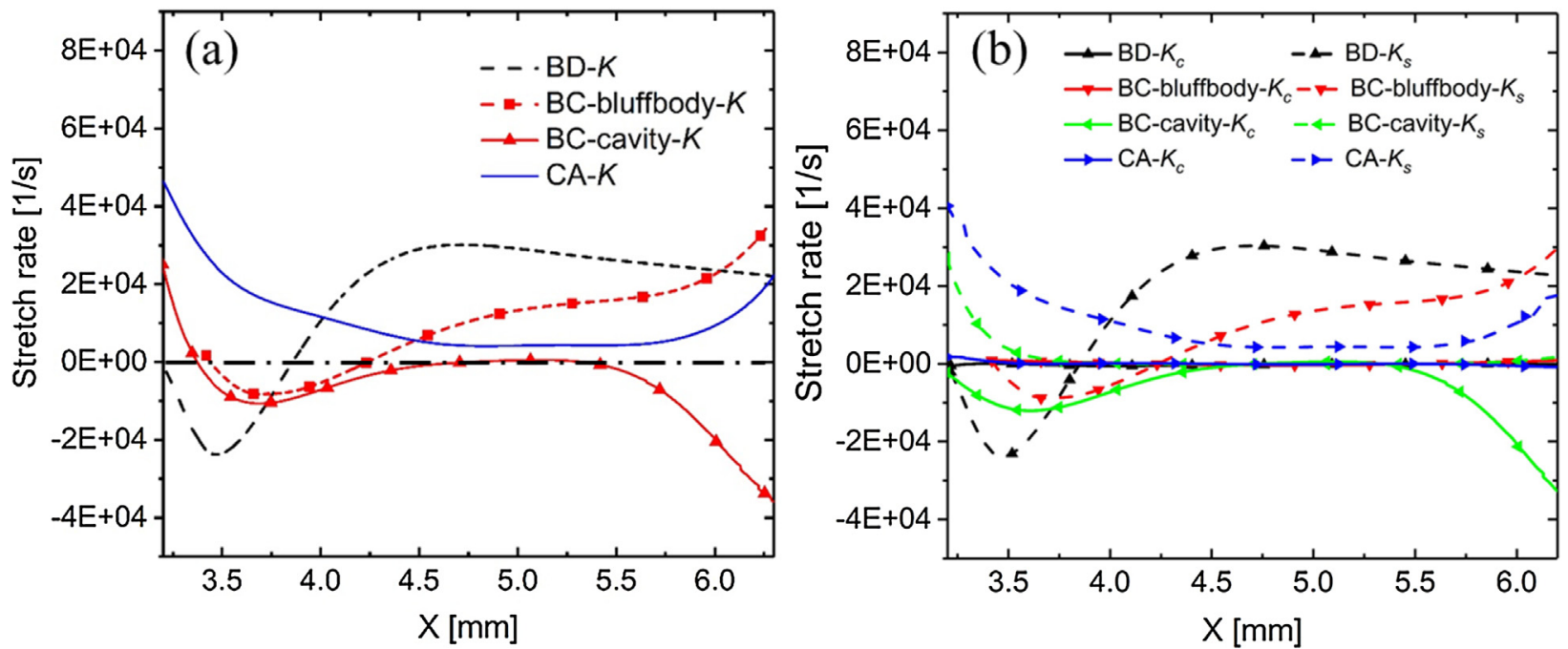

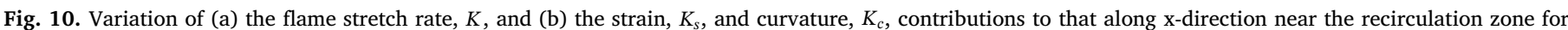
different combustors $\left(V_{\text {in }}=36 \mathrm{~m} / \mathrm{s}\right)$. 
mixture normalized by the total heat of combustion, $\Delta H_{\text {total }}$, is shown in Fig. 11(a). The increase of $\Delta H_{\text {total }}$ indicating a heat feedback from the wall to the gas mixture, and vice versa. There is a significant preheating zone before the entry of the cavity for CA and BC combustors, followed by a rapid decrease of $\Delta H_{\text {total }}$ within the cavity zone due to the heat loss of gas mixture. For the $\mathrm{BD}$ combustor, the preheating zone is much longer than the former, which is coincide with the prolonged flame shown in Fig. 6(a). The small peak inserted in the preheat zone of the $\mathrm{BD}$ profile is attributed to the heat conjugate between flame and the bluff body. The $\mathrm{BC}$ case shows the most prominent preheating effect $\left(\Delta H_{\text {total }}>0\right)$ among the three combustors $(3.07 \%$ for the BC combustor; $1.38 \%$ for the CA combustor; $0.92 \%$ for the BD combustor). To specify the thermal effects of different flame holders, the heat flux at the interfaces between the flame and the flame holders (bluff-body or cavity) for different combustors is shown in Fig. 11(b). The wall heat flux varies significantly on the cavity wall from $1446 \mathrm{~W}$ of the CA to the $1236 \mathrm{~W}$ of the $\mathrm{BC}$, while a negligible change observed on the bluff-body wall from the $\mathrm{BD}$ to the $\mathrm{BC}$ cases. The larger heat flux of the $\mathrm{BC}$ case can be interpreted by: (1) a higher velocity in the recirculation zone induces higher convective heat transfer, (2) a closer distance between flame and walls induces larger temperature gradient. The more intensive preheating effects ahead of the cavity and the larger heat flux through the cavity wall combined with the negative flame stretch rate in the $\mathrm{BC}$ combustor account for the higher $Y_{O H}$ in the entrance and the lower $Y_{O H}$ in the middle of the cavity zone, respectively. Besides, as shown in Fig. 11(a), the BD combustor shows the lowest total heat loss $\left(\Delta H_{\text {total }}(x=18 \mathrm{~mm})\right)$, and the CA combustors endured the largest heat loss due to the high and uniform wall temperature.

The non-unity Lewis number effect $(\mathrm{Le}<1)$ and combustion incompleteness induced by the flame stretch are the major mechanisms for the strengthened combustion intensity behind the bluff-body in the BC combustor. It should be noted that the conjugate heat transfer between the flame and the bluff body plays a significant role in flame stability [42]. Nevertheless, the effects of that on BC and BD are almost equal as shown in Fig. 11(b). For the decrease of combustion intensity in the cavity of the $\mathrm{BC}$ combustor, a larger heat loss should be considered except the flame stretch effects. Overall, the enhancement effect of bluff-body compensates the reduction in cavity zones, which is crucial for the improved performances of the $\mathrm{BC}$ combustor.

\subsection{Effects of blockage ratio of bluff-body}

3.3.1. Performance of combustors under different blockage ratios Comparisons of the combustion efficiency and split-off velocities

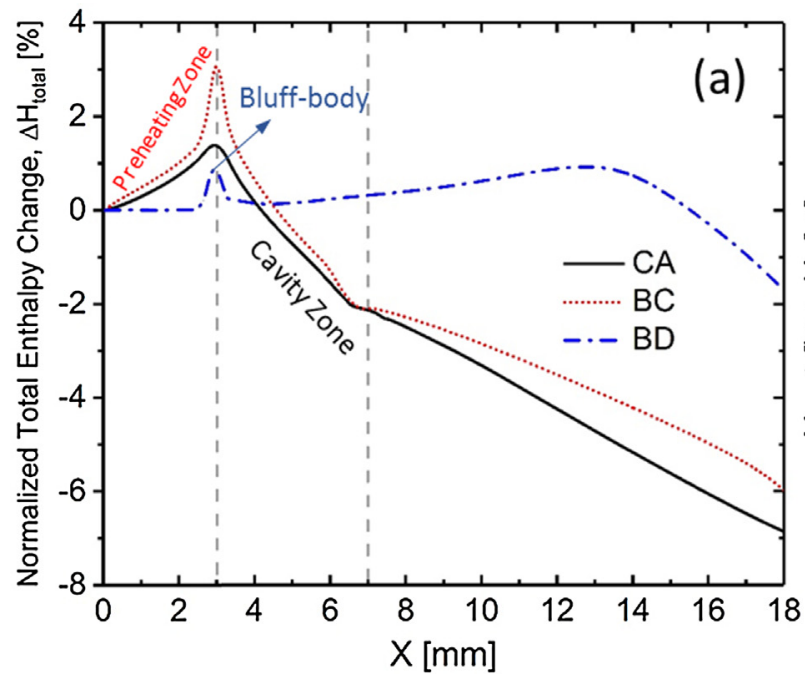

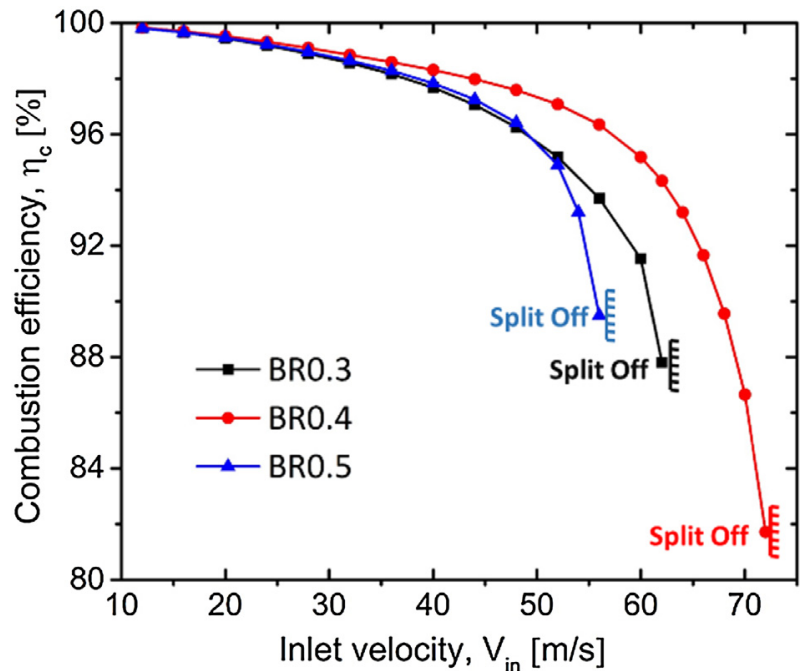

Fig. 12. Combustion efficiency versus inlet velocity and the split-off limits for three different block ratios for BC combustor.

between BC combustors with different blockage ratios are illustrated in Fig. 12. It can be found that BR has a non-monotonic effect on $\eta_{c}$ especially under relative high inlet velocities. The highest $\eta_{c}$ is observed in the $\mathrm{BC}$ combustor with $\mathrm{BR}=0.4$ among the three cases with BRs varying from 0.3 to 0.5 . Besides, the "split off" phenomenon occurs firstly in the $\mathrm{BR}=0.5$ case at $V_{\text {in }}=56 \mathrm{~m} / \mathrm{s}$ followed by the $\mathrm{BR}=0.3$ at $62 \mathrm{~m} / \mathrm{s}$ and $\mathrm{BR}=0.4$ case at $72 \mathrm{~m} / \mathrm{s}$.

Fig. 13 shows the variations of flame fronts and the corresponding profiles of $\mathrm{H}_{2}$ consumption ratio under various $V_{\text {in }}$ for different blockage ratio cases. The flame fronts are prolonged and the flame zones behind the central bluff-body are necked with the increase of $V_{i n}$. At $V_{i n}=20 \mathrm{~m} /$ $\mathrm{s}$, the flame fronts are similar, where the $\mathrm{BR}=0.3$ case has the longest flame front. As $V_{\text {in }}$ increases to $48 \mathrm{~m} / \mathrm{s}$, the flame front pattern of $\mathrm{BR}=0.5$ become quite different from the others, where a visible concave curve (circled by black dash line) is formed along the two sides of the bluff-body. The necked flame fronts behind the aft of the cavity shrinks to the center and almost overlapped with each other. Finally, the flame fronts transformed into the "double V" pattern stabilized by the bluff-body and the cavity respectively due to the flame split near the aft of the cavity at $V_{\text {in }}=56 \mathrm{~m} / \mathrm{s}$. The variations of the corresponding $\mathrm{H}_{2}$ consumption ratio along the streamwise of the combustors are illustrated in Fig. 13(b). For $V_{\text {in }}=20 \mathrm{~m} / \mathrm{s}$ cases, the profiles of consumption

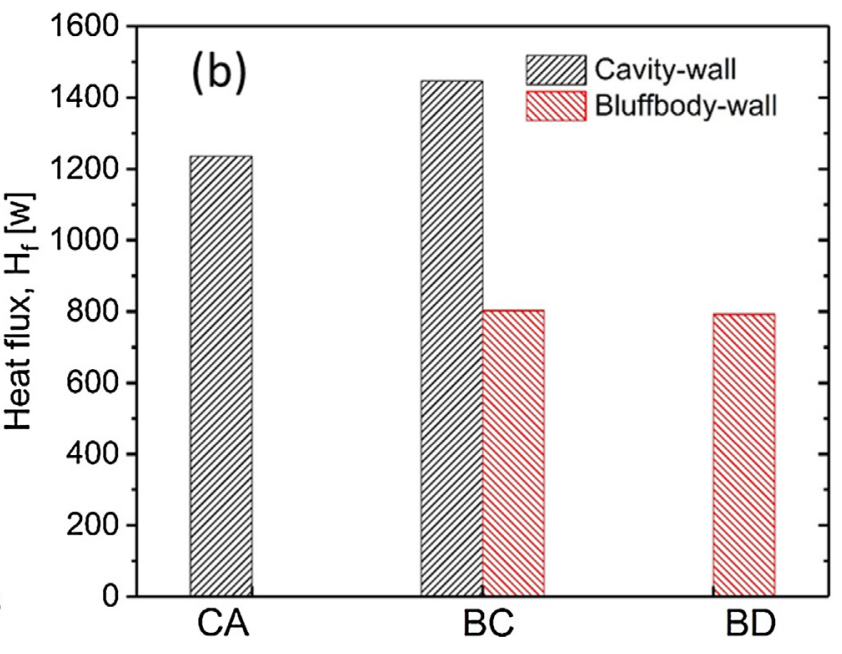

Fig. 11. (a) Normalized total enthalpy change and (b) heat flux at the interfaces between the flame and flame holders for different combustors at $V_{\text {in }}=36 \mathrm{~m} / \mathrm{s}$. 


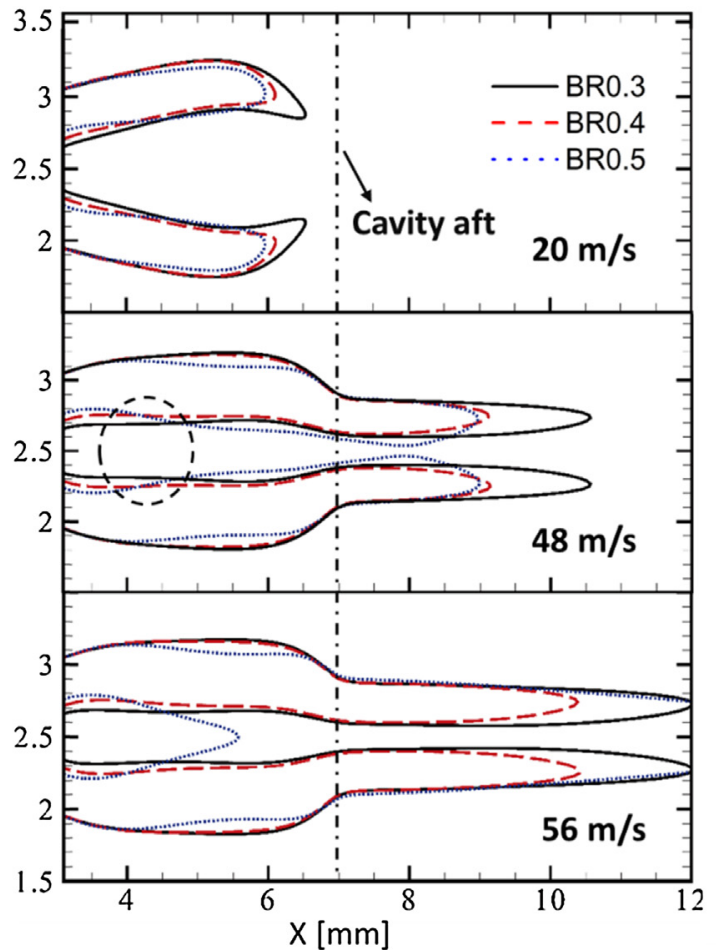

(a)

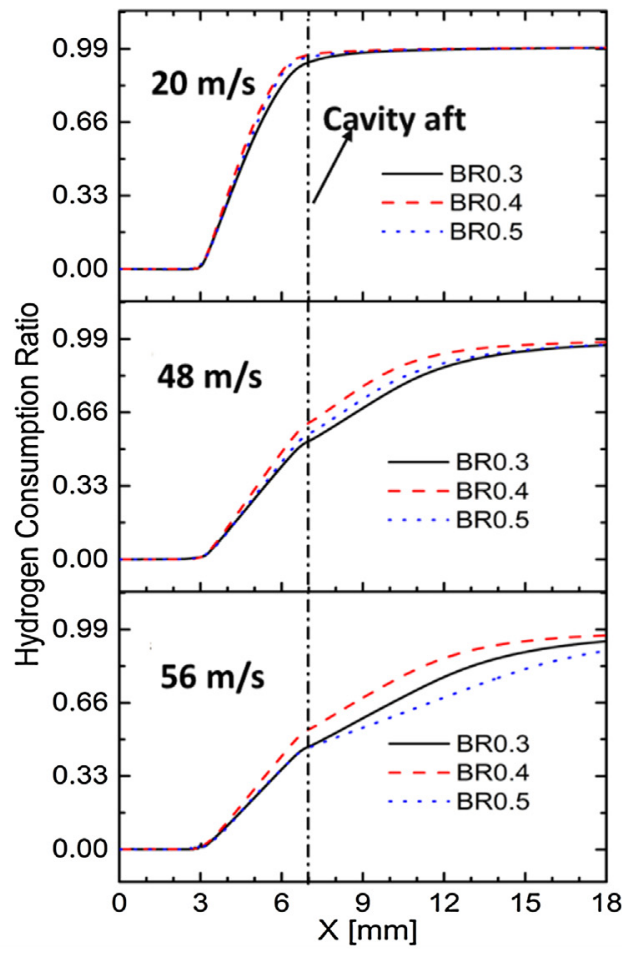

(b)
Fig. 13. Comparison of (a) flame fronts and (b) profiles of $\mathrm{H}_{2}$ consumption ratio along streamwise direction between three different blockage ratios under various inlet velocities. ratio under different blockage ratios are similar, coinciding with the locations of the flame fronts in Fig. 13(a). The profiles of BR $=0.4$ and $\mathrm{BR}=0.5$ are almost overlapped with each other and are slightly higher than that in the $\mathrm{BR}=0.3$ case within the cavity zone albeit the nearly identical value at the outlet (i.e. combustion efficiency). As the $V_{\text {in }}$ is further increased, the consumption ratio of $\mathrm{H}_{2}$ decreases significantly, where most of the hydrogen escape from cavity zones $(x=7 \mathrm{~mm})$ for the three different blockage ratio cases. Moreover, the $\mathrm{BR}=0.5$ case undergoes the largest relative reduction among the three cases as demonstrated in Fig. 13(b). The hydrogen consumption ratio profile of $\mathrm{BR}=0.5$ shows a different tendency at $V_{\text {in }}=56 \mathrm{~m} / \mathrm{s}$ with a nearly linear increase of consumption ratio along streamwise direction, corresponding to the transition from the "M-type" to the "double-V" type flame.

\subsubsection{Flow and flame interactions under different blockage ratios}

Fig. 14 shows the contours of $Y_{\mathrm{OH}}$ (upper) overlaid with streamlines and $Y_{\mathrm{H}_{2}}$ (lower) accompanied by contour lines of $v_{x}$ for three BRs at $v_{\text {in }}=48 \mathrm{~m} / \mathrm{s}$, near the split off limit of BR $=0.5$. In the bluff-body zones, the flow velocity increases near the recirculation zones with the increase of BR. High velocity gradients occurs in the vicinity of the entrance and aft of the cavity, resulting in large flow strain rate there. As regards to the flame stabilized by bluff-body, the RZ-Bs expand accompanied with higher $Y_{\mathrm{OH}}$ as the BR is increased [43]. $Y_{\mathrm{OH}}$ at the end of the RZ-B in the $\mathrm{BR}=0.5$ combustor decreases rapidly followed by a thinner flame zone, comparing with the $\mathrm{BR}=0.3$ and $\mathrm{BR}=0.4$ cases. Meanwhile, a larger $Y_{\mathrm{H}_{2}}$ is observed behind the RZ-B for the $\mathrm{BR}=0.5$ case, indicating incomplete combustion. For the flame stabilized in the cavity, the distributions of $Y_{\mathrm{OH}}$ are similar for $\mathrm{BR}=0.3$ and $\mathrm{BR}=0.4$, and is lower for BR $=0.5$ albeit a larger RZ-C. Overall, the BR $=0.4$ case shows the highest reactivity indicated by the $Y_{\mathrm{OH}}$ compared with the others two cases due to the coupling effects of the central bluff-body and the side cavity, and consequently the highest combustion efficiency shown in Fig. 12.

To quantify the interaction between flame and flow under different $\mathrm{BRs}$, the flame stretch rates at the flame fronts are calculated at $v_{\text {in }}=48$ $\mathrm{m} / \mathrm{s}$ as depicted in Fig. 15 (the negative burning velocity regions are eliminated). Along the flame fronts anchored by bluff-body, the flame stretch rate changes from negative at the side of RZ-Bs to positive near the end of RZ-Bs. Among the three different BRs, the BR $=0.5$ case produces the largest negative stretch due to the strong shear flow combined with the drastic concave flame fronts aside the RZ-B. The remarkable negative stretch inhibits the combustion intensity and consequently reduces the $Y_{\mathrm{OH}}$ near the end of the RZ-B of the $\mathrm{BR}=0.5$ case, as depicted in Fig. 14(c). Moreover, the more intense positive stretch attributed to the strong flow strain rate between $x=56 \mathrm{~mm}$ at $\mathrm{BR}=0.5$ suppresses the combustion completeness and thus diminishes the $Y_{\mathrm{OH}}$ behind the RZ-B. The reduction of combustion intensity in the RZ-B and the subsequent incomplete combustion result in the continuously shrinking of the flame zone anchored by bluff-body, eventually split the flame near the excessive stretch region, i.e., the cavity aft for $\mathrm{BR}=0.5$. Fig. 15(b) presents the flame stretch rate near the RZCs for three different blockage ratios. Generally, there is a high positive flame stretch rate near the entrance of the cavity followed by a nearly zero value in the middle and a high positive stretch rate near the cavity aft, except a weak negative stretch rate in the cavity aft for $\mathrm{BR}=0.5$. From Fig. 14, the high positive stretch at the entrance and the outlet of the cavity zone is induced by the strong flow strain rate and the positive curvature at the flame fronts. The observation that the flame front is almost parallel to the streamlines indicates weak stretch rate in the middle of the cavity. While a weak negative stretched curvature (concave towards the reactants) formed near the cavity aft at $\mathrm{BR}=0.5$ causes the mildly stretched flame in Fig. 14(c). The negative stretch rate combined with the reduced residence time due to the larger flow velocity behind the recirculation zone are responsible for the lower $Y_{\mathrm{OH}}$ in the cavity zones of $\mathrm{BR}=0.5$. Generally, with increase of blockage ratio, the recirculation zones induced by the central bluff-body and the side cavity are both enlarged, meanwhile the magnitudes of the flame stretch rate and the flow velocity behind recirculation zone increase. The competition between the promoting and prohibitive effects result in non-monotonic variations of the combustion efficiency and the critical velocity with the increase of blockage ratio. Moreover, the heat 


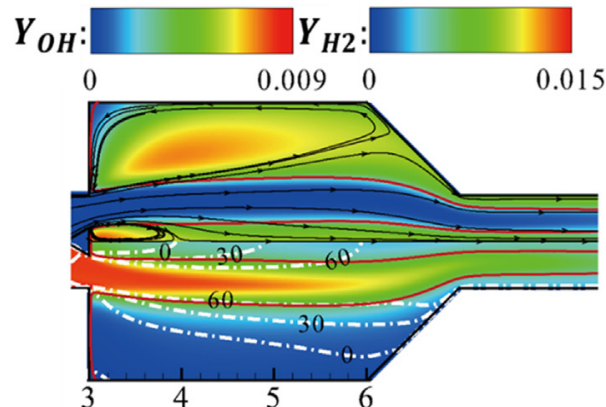

(a) $\mathrm{BR}=0.3$

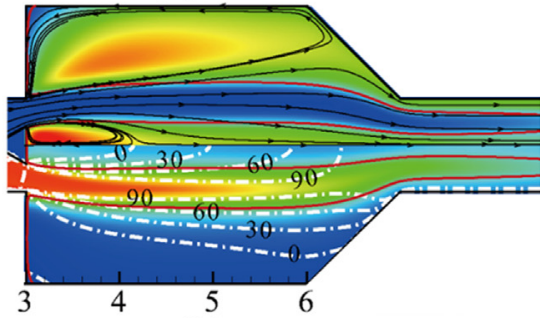

(b) $B R=0.4$

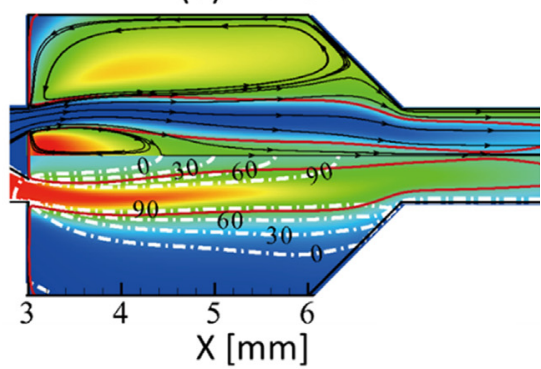

(c) $B R=0.5$

Fig. 14. Contours of $Y_{\mathrm{OH}}$ overlaid with streamlines (upper part) and Contours of $Y_{\mathrm{H}_{2}}$ overlaid with contour lines of $x$-component velocity, $v_{x}$ (lower part) for different blockage ratios $\left(V_{i n}=48 \mathrm{~m} / \mathrm{s}\right)$.

loss through inner surfaces of bluff-body and cavity under different BRs are similar with negligible differences, thus the results are not shown here. Fan et al. [43] also showed that compared with stretching effects in the shear layers, the effects of heat loss are negligible when analyzing the flame stability for bluff-body type micro-combustors with various BRs. However, a monotonic increase of the blow-off limit with the increase of BR was found, which is inconsistent with the non-monotonic dependence observed in the bluff-body augmented cavity combustor in this study. The non-monotonic dependences were also reported in the studies on the bluff-body coupled backward-step combustor [44] and methane fueled micro-channel combustor [45]. The relationship between BR and flame stability can be varied with the configuration and fuel type of the combustor, a further comprehensive analysis of the effects of BR on the complicated flow and flame structures will give an insight into the general mechanisms for the flame stabilization. This will be a subject in our future work.

\section{Conclusions}

The combined effects of a central bluff-body and side dual-cavity on combustion enhancement in the microchannel are investigated by numerical simulation with the detailed gas-phase chemistry and conjugate heat transfer. Two types of flame structures are observed, i.e., the "Mtype" flame when the flames anchored by the bluff-body and cavity flame holders merge, and the "double- $V$ " flame when the flames split. The merged "M-type" flame promotes the combustion completeness and contributes to the uniform wall temperature. The flow recirculation zone enlarges and the high flame stretch rate mitigates behind the bluffbody with the aid of cavity, which improves the flame stability significantly as the split-off limit increases from $40 \mathrm{~m} / \mathrm{s}$ in single bluffbody to $56 \mathrm{~m} / \mathrm{s}$ in cavity combined configurations with the bluff-body blockage ratio $\mathrm{BR}=0.5$. The higher performances of the bluff-body and cavity synergetic combustor are observed independent with the equivalence ratio ranging from 0.4 to 0.5 . A moderate equivalence ratio is favored to achieve a stable and high efficiency $\mathrm{H}_{2}$ /air premixed flame in the proposed combustor. As the BR increases from 0.3 to 0.5 , the recirculation zones induced by the bluff-body and cavity extends accompanied with the enhanced flame stretch rate and the increased flow velocity. The competition between the promoting and prohibitive effects result in non-monotonic dependence between the combustors performance and the BR. The optimal BR is 0.4 with the split-off limit being $72 \mathrm{~m} / \mathrm{s}$. These features of the proposed configuration show the potential of application in micro power supply systems.

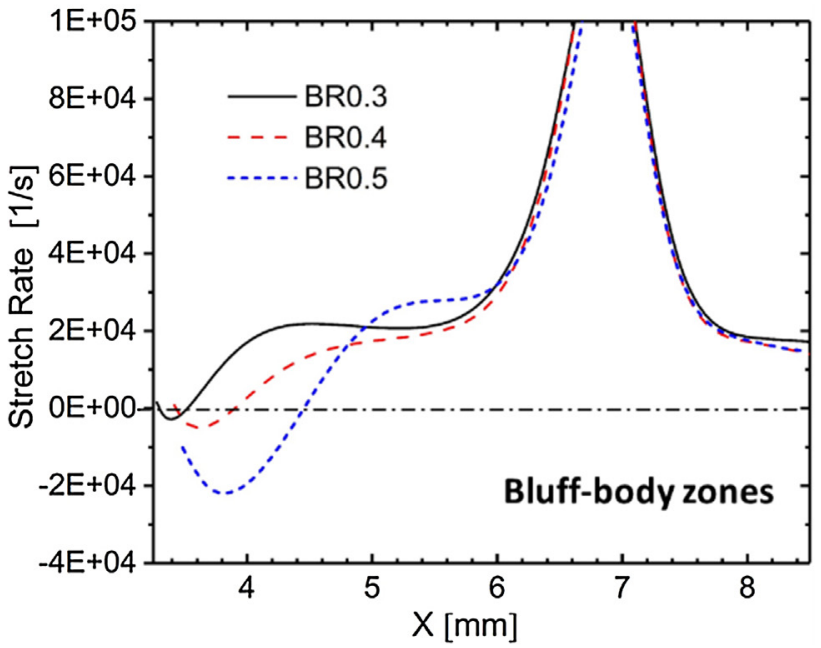

(a)

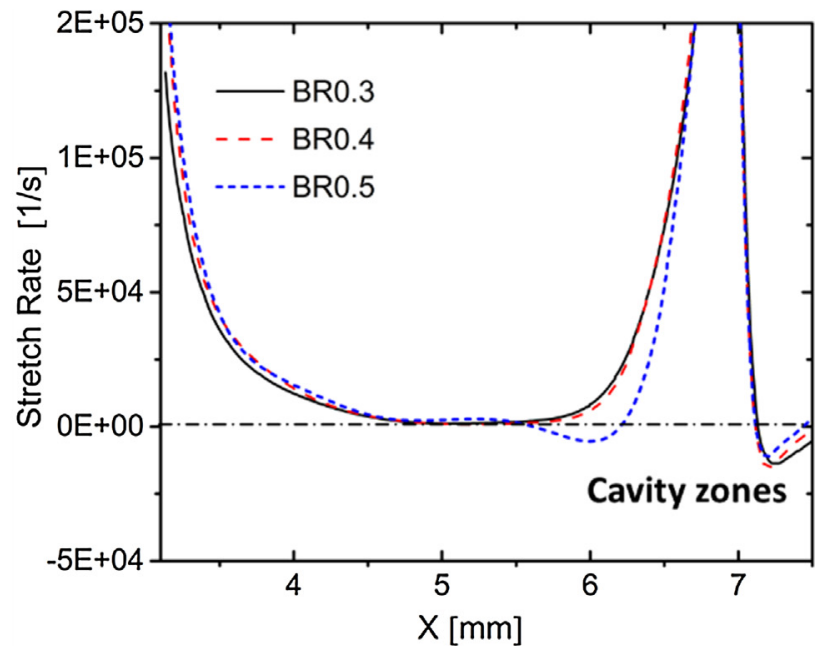

(b)

Fig. 15. The profiles of the flame stretch rate along $x$-direction near (a) bluff-body and (b) cavity zones for BC combustors under blockage ratios, $0.3,0.4$ and 0.5 $\left(v_{\text {in }}=48 \mathrm{~m} / \mathrm{s}\right)$. 


\section{CRediT authorship contribution statement}

Zheng Zhang: Conceptualization, Methodology, Validation, Investigation, Data curation, Writing - original draft, Writing - review \& editing, Visualization. Kun Wu: Writing - review \& editing, Conceptualization. Wei Yao: Writing - review \& editing, Funding acquisition. Richard Yuen: Software. Jian Wang: Supervision, Funding acquisition.

\section{Declaration of Competing Interest}

The authors declare that they have no known competing financial interests or personal relationships that could have appeared to influence the work reported in this paper.

\section{Acknowledgements}

This work was supported by the National Key Technologies R\&D Program of China (Grant No. 2018YFC0809500), Training Program of the Major Research Plan of National Natural Science Foundation of China (Grant No. 91641110).

\section{References}

[1] Ju YG, Maruta K. Microscale combustion: technology development and fundamental research. Progr Energy Combust Sci 2011;37:669-715.

[2] Fernandez-Pello AC. Micropower generation using combustion: issues and approaches. Proc Combust Inst 2002;29:883-99.

[3] Daou J, Matalon M. Influence of conductive heat-losses on the propagation of premixed flames in channels. Combust Flame 2002;128:321-39.

[4] Raimondeau S, Norton D, Vlachos DG, Masel RI. Modeling of high-temperature microburners. Proc Combust Inst 2002;29:901-7.

[5] Maruta K, Kataoka T, Kim NI, Minaev S, Fursenko R. Characteristics of combustion in a narrow channel with a temperature gradient. Proc Combust Inst 2005;30:2429-36.

[6] Norton DG, Vlachos DG. Combustion characteristics and flame stability at the microscale: a CFD study of premixed methane/air mixtures. Chem Eng Sci 2003;58:4871-82

[7] Kim NI, Kato S, Kataoka T, Yokomori T, Maruyama S, Fujimori T, et al. Flame stabilization and emission of small Swiss-roll combustors as heaters. Combust Flame 2005;141:229-40.

[8] Kuo CH, Ronney PD. Numerical modeling of non-adiabatic heat-recirculating combustors. Proc Combust Inst 2007;31:3277-84.

[9] Zuo W, Jiaqiang E, Peng Q, Zhao X, Zhang Z. Numerical investigations on a comparison between counterflow and coflow double-channel micro combustors for micro-thermophotovoltaic system. Energy 2017;122:408-19.

[10] Ju YG, Choi CW. An analysis of sub-limit flame dynamics using opposite propagating flames in mesoscale channels. Combust Flame 2003;133:483-93.

[11] Bani S, Pan J, Tang A, Lu Q, Zhang Y. Numerical investigation of key parameters of the porous media combustion based micro-thermophotovoltaic system. Energy 2018;157:969-78.

[12] Li J, Li QQ, Shi JR, Liu XL, Guo ZL. Numerical study on heat recirculation in a porous micro-combustor. Combust Flame 2016;171:152-61.

[13] Brambilla A, Frouzakis CE, Mantzaras J, Tomboulides A, Kerkemeier S, Boulouchos K. Detailed transient numerical simulation of H-2/air hetero-/homogeneous combustion in platinum-coated channels with conjugate heat transfer. Combust Flame 2014;161:2692-707.

[14] Pan J, Zhang R, Lu Q, Zha Z, Bani S. Experimental study on premixed methane-air catalytic combustion in rectangular micro channel. Appl Therm Eng 2017;117:1-7.

[15] Wang Y, Yang W, Zhou J, Yang H, Yao Y, Cen K. Heterogeneous reaction characteristics and its effects on homogeneous combustion of methane/air mixture in microchannels II. Chemical analysis. Fuel 2019;235:923-32.

[16] Khandelwal B, Deshpande AA, Kumar S. Experimental studies on flame stabilization in a three step rearward facing configuration based micro channel combustor. Appl Therm Eng 2013;58:363-8.

[17] Yang WM, Chou SK, Shu C, Li ZW, Xue H. Combustion in micro-cylindrical combustors with and without a backward facing step. Appl Therm Eng 2002;22:1777-87.

[18] Peng Q, Wu Y, Jiaqiang E, Yang W, Xu H, Li Z. Combustion characteristics and thermal performance of premixed hydrogen-air in a two-rearward-step micro tube. Appl. Energy 2019;242:424-38.

[19] Bazooyar B, Gohari Darabkhani H. Analysis of flame stabilization to a thermophotovoltaic micro-combustor step in turbulent premixed hydrogen flame. Fuel 2019;257:115989.

[20] Wan JL, Fan AW, Maruta K, Yao H, Liu W. Experimental and numerical investigation on combustion characteristics of premixed hydrogen/air flame in a micro-combustor with a bluff body. Int J Hydrog Energy 2012;37:19190-7.

[21] Bagheri G, Hosseini SE, Wahid MA. Effects of bluff body shape on the flame stability in premixed micro-combustion of hydrogen air mixture. Appl Therm Eng 2014;67:266-72.

[22] Yan Y, He Z, Xu Q, Zhang L, Li L, Yang Z, et al. Numerical study on premixed hydrogen/air combustion characteristics in micro-combustor with slits on both sides of the bluff body. Int J Hydrog Energy 2019;44:1998-2012.

[23] Li YH, Chen GB, Hsu HW, Chao YC. Enhancement of methane combustion in microchannels: effects of catalyst segmentation and cavities. Chem Eng J 2010;160:715-22.

[24] Wan JL, Yang W, Fan AW, Liu Y, Yao H, Liu W, et al. A numerical investigation on combustion characteristics of $\mathrm{H}-2$ /air mixture in a microcombustor with wall cav ities. Int J Hydrogen Energy 2014;39:8138-46.

[25] Wan JL, Fan AW, Yao H, Liu W. A non-monotonic variation of blow-off limit of premixed CH4/air flames in mesoscale cavity-combustors with different thermal conductivities. Fuel 2015;159:1-6.

[26] Wan JL, Fan AW, Liu Y, Yao H, Liu W, Gou XL, et al. Experimental investigation and numerical analysis on flame stabilization of $\mathrm{CH} 4$ /air mixture in a mesoscale channel with wall cavities. Combust Flame 2015;162:1035-45.

[27] Wan JL, Fan AW, Yao H, Liu W. Experimental investigation and numerical analysis on the blow-off limits of premixed CH4/air flames in a mesoscale bluff-body combustor. Energy 2016;113:193-203.

[28] Wan JL, Fan AW. Effect of solid material on the blow-off limit of CH4/air flames in a micro combustor with a plate flame holder and preheating channels. Energy Convers Manage 2015;101:552-60.

[29] Wan JL, Fan AW, Yao H. Effect of the length of a plate flame holder on flame blowout limit in a micro-combustor with preheating channels. Combust Flame 2016;170:53-62.

[30] Li J, Zhao Z, Kazakov A, Dryer FL. An updated comprehensive kinetic model of hydrogen combustion. Int J Chem Kinet 2004;36:566-75.

[31] Wan JL, Fan AW, Yao H, Liu W. Effect of thermal conductivity of solid wall on combustion efficiency of a micro-combustor with cavities. Energy Convers Manage 2015;96:605-12.

[32] Su Y, Song JL, Chai JL, Cheng Q, Luo ZX, Lou C, et al. Numerical investigation of a novel micro combustor with double-cavity for micro-thermophotovoltaic system. Energy Convers Manage 2015;106:173-80.

[33] Chen Y-C, Bilger RW. Experimental investigation of three-dimensional flame-fron structure in premixed turbulent combustion: II. Lean hydrogen/air Bunsen flames. Combust Flame 2004;138:155-74.

[34] Spadaccini CM, Mehra A, Lee J, Zhang X, Lukachko S, Waitz IA. High power density silicon combustion systems for micro gas turbine engines. J Eng Gas Turbines Power 2003;125:709-19.

[35] Xu M, Yuan J, Han C, Zheng C. Investigation of particle dynamics and pulverized coal combustion in a cavity bluff-body burner. Fuel 1995;74:1913-7.

[36] Michaels D, Shanbhogue SJ, Ghoniem AF. The impact of reactants composition and temperature on the flow structure in a wake stabilized laminar lean premixed CH4/ H2/air flames; mechanism and scaling. Combust Flame 2017;176:151-61.

[37] Candel SM, Poinsot TJ. Flame stretch and the balance equation for the flame area Combust Sci Technol 1990;70:1-15.

[38] Kedia KS, Ghoniem AF. The blow-off mechanism of a bluff-body stabilized laminar premixed flame. Combust Flame 2015;162:1304-15.

[39] Wang J, Wei Z, Yu S, Jin W, Xie Y, Zhang M, et al. Effects of stretch and preferential diffusion on tip opening of laminar premixed Bunsen flames of syngas/air mixtures. Fuel 2015;148:1-8.

[40] Kedia KS, Ghoniem AF. The anchoring mechanism of a bluff-body stabilized laminar premixed flame. Combust Flame 2014;161:2327-39.

[41] Law CK. Combustion physics. Cambridge University Press; 2010.

[42] Michaels D, Ghoniem AF. Impact of the bluff-body material on the flame leading edge structure and flame-flow interaction of premixed $\mathrm{CH} 4 /$ air flames. Combust Flame 2016;172:62-78.

[43] Fan AW, Wan JL, Liu Y, Pi BM, Yao H, Maruta K, et al. The effect of the blockage ratio on the blow-off limit of a hydrogen/air flame in a planar micro-combustor with a bluff body. Int J Hydrog Energy 2013;38:11438-45.

[44] Jia-qiang E, Huang HJ, Zhao XH. Numerical investigations on effects of bluff body in flat plate micro thermo photovoltaic combustor with sudden expansion. J Central South Univ 2016;23:975-82.

[45] Yan Y, Yan H, Zhang L, Li L, Zhu J, Zhang Z. Numerical investigation on combustion characteristics of methane/air in a micro-combustor with a regular triangular pyramid bluff body. Int J Hydrogen Energy 2018;43:7581-90. 